\title{
Las filosofías en la teología de Justino Mártir
}

\author{
Viviana Laura Félix \\ PONTIFICIA UNIVERSIDAD CATÓLICA ARGENTINA \\ vivifelix13@yahoo.com.ar
}

Resumen: La teología de Justino constituye uno de los primeros intentos de reflexión sobre la Revelación integrando categorías filosóficas a la misma. Si bien no es el único, es un representante significativo de este modo de hacer teología en el siglo II y que tendrá una amplia recepción en los siglos posteriores.

En este trabajo intentaremos señalar algunos de los elementos que toma de las filosofías de su tiempo. A partir de esos señalamientos, trataremos de caracterizar el modo en el que se sirve de las distintas doctrinas filosóficas, con sus logros y límites. Finalmente, mediante el acercamiento antes expuesto, intentaremos valorar con mayor precisión el aporte de Justino a la historia de la teología y al diálogo razón y fe.

Palabras clave: Justino mártir, Fe y razón, Cristología, Atributos divinos, Platonismo medio, Padres apologistas.

Abstract: The theology of Justin Martyr marks one of the first attempts to integrate philosophical categories into a reflection on Revelation. Although not the only one, he is an important representative of this theological style during the second century, a method which would be broadly influential in later centuries.

The goal of this article is, firstly, to bring to the fore some of the elements Justin borrows from the philosophies of his own era. Building on that groundwork, I aim to focus on the way he employs different philosophical doctrines, with all their potential and their limitations. Finally, working from such a basis, I intend to come to a more accurate evaluation of Justin's contributions to the history of theology and to the dialogue between faith and reason.

Keywords: Justin martyr, Faith and reason, Christology, Divine attributes, Middle platonism, Apologetic fathers 
La teología de Justino constituye uno de los primeros intentos de reflexión sobre la Revelación, integrando categorías filosóficas a la misma. Si bien no es el único, es un representante significativo de este modo de hacer teología en el siglo II y que tendrá una amplia recepción en los siglos posteriores.

En este trabajo intentaremos señalar algunos de los elementos que toma de las filosofías de su tiempo. A partir de esos señalamientos, trataremos de caracterizar el modo en el que se sirve de las distintas doctrinas filosóficas. Finalmente, mediante el acercamiento antes expuesto, intentaremos valorar con mayor precisión el aporte de Justino a la historia de la teología y al diálogo razón y fe.

Justino accede a la fe cristiana con una formación filosófica previa. De ella se servirá para presentar, en un ambiente que se había tornado hostil, la racionalidad del cristianismo. La hostilidad hacia el cristianismo, que desde principios del siglo II mayoritariamente se daba en sectores populares, había empezado a manifestarse también entre los intelectuales ${ }^{1}$. Tácito y Suetonio recogen los rumores populares que circulaban contra los cristianos, como también sucede con Frontón (100-166) uno de los eruditos más críticos del cristianismo, que en lugar de argumentar con un discurso filosófico, recopila los vicios atribuidos por la gente común a los cristianos, subrayando el carácter popular del grupo: desprecian la muerte en base a una esperanza falaz, porque no es una idea que proceda de la razón ${ }^{2}$. Podríamos señalar entre los primeros representantes de esta hostilidad desde el mundo intelectual a Epicteto y Marco Aurelio. El primero destaca la actitud del cristiano ante el tirano y la falta de temor a la muerte, pero no ve en ello una virtud, por no tratarse de una actitud derivada de la razón sino de la costumbre 3 . Marco Aurelio presenta la actitud del cristiano ante la muerte como contrapuesta a la serenidad del filósofo frente a la muerte, criticando al cristiano por su teatralidad e irracionalidad, siendo su actitud el resultado de una mera oposición: "Mas esta disposición, que proceda de una decisión personal, no de una

1 Cf. D. Álvarez Cineira, "El cristianismo en el Imperio romano (siglos I-II), en Así empezó el cristianismo, S. Gujjarro (ed.) (Ed. Verbo Divino, Estella, Navarra, 2010) 405-410. Seguimos a este autor para presentar el marco histórico del siglo II, cfr. 405-419.

2 Las críticas de Frontón se conservan en el Octavio de Minucio Felix, 8 y 9.

3 Cf. Eрістето, Disertaciones por Arriano, IV 7, 1-7 trad. introd. y notas Ortiz García, P. (Gredos, Madrid 1993). 
simple oposición, como los cristianos, sino fruto de una reflexión, de un modo serio y, para que pueda convencer a otro, exenta de teatralidad" El elemento común en los detractores no es la conducta en sí misma, sino la falta de racionalidad como causa esta. Los intelectuales convertidos al cristianismo, y este es el caso de Justino, por lo tanto, deberán defender el carácter racional de la fe que abrazan. Entre los intelectuales paganos que refieren al cristianismo hacia la mitad del siglo II Álvarez Cineira, siguiendo a Benko, señala que la posición de Galeno (129-199) supone una novedad en la actitud ${ }^{5}$. Valora la eficacia de la enseñanza cristiana, por la cual los cristianos acceden a una conducta moral semejante a la de los filósofos, e incluso, pone a seguidores de las enseñanzas de Cristo y de Moisés como formando una escuela filosófica elemental. Si bien los considera dependientes de una actitud fideísta, esta nueva consideración de la vida cristiana como vida filosófica supone o es eco de un nuevo estatus del que se servirá Justino para presentar la racionalidad del cristianismo ${ }^{6}$.

4 Marco Aurelio, Meditaciones, X 3, trad. y notas Bach Pellicer, R. (Gredos, Madrid, 1983).

5 “...uno podría enseñar más fácilmente una doctrina distinta a los seguidores de Moisés o de Cristo que a los médicos y filósofos que permanecen anclados en

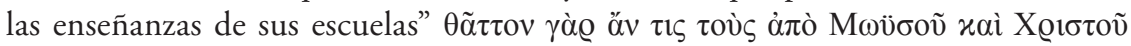

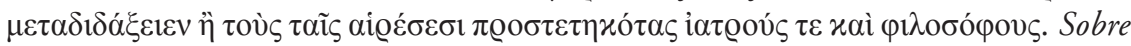
la variedad de las pulsaciones 3, 3 (8.657.1). Un pasaje que se conserva en árabe describe la posición de Galeno: "La mayoría de la gente no es capaz de seguir con la mente un discurso demostrativo continuo, y por esto deben ser enseñados con parábolas. Así, vemos a nuestro alrededor a los llamados cristianos que buscan su fe únicamente en parábolas y en milagros. Sin embargo, consta que observan una conducta análoga [a la de los filósofos]. En efecto, podemos observar todos los días que desprecian la muerte y lo que la acompaña, e igualmente que aborrecen las relaciones sexuales. De hecho, se hallan entre ellos no solo hombres, sino también mujeres que durante toda su vida han observado la más absoluta castidad. También algunos han mantenido esta disciplina respecto a la comida y a la bebida, y en la búsqueda de la justicia han alcanzado un rigor no inferior al de los verdaderos filósofos" (traducción de Álvarez Cineriar, cf. op. cit., p. 413, n. 71) El texto está tomado desde S. Benko, "Pagan Criticism of Christianity During the First Two Centuries A.D.2 ANRWII.23.2 (1980) 1055-1118 (1099), quien a su vez lo toma de R. Walzer, Galen on Jews and Christians, Oxford University Press, London, 1949, pp. 14-15.

6 Benko en una obra posterior propone el intento de Justino y los otros apologistas como la causa de esta nueva percepción del cristianismo que se manifiesta en Galeno, quien se había trasladado a Roma hacia el 161 y, salvo una estadía entre 166169 en Pérgamo, permaneció allí hasta su muerte. El martirio de Justino sucedió 
En su "escuela de filosofía cristiana" buscará mostrar con claridad la racionalidad del cristianismo, por el camino de la semejanza con la cultura helenística, pero también resaltará la especificidad, y por lo tanto, la diferencia con las doctrinas helenísticas. El contexto de sus enseñanzas y de la reflexión que las sustenta, no solo tiene como interlocutores a los paganos cultos, sino también a grupos de cristianos cultos cuyas afirmaciones presenta como errores en la comprensión de la verdadera fe. Su llegada a Roma para enseñar filosofía habría sido a instancias del obispo Higinio, quien requería de su bagaje filosófico-cultural para responder a estos maestros heterodoxos, Marción, Valentín y Cerdón. De cara a estos representantes del gnosticismo tendrá también que explicitar la verdadera doctrina cristiana.

Por lo tanto, la teología de Justino no es el resultado de una pura tarea especulativa, sino que se halla profundamente enmarcada en la didascalia y la apologética, con interlocutores muy precisos a los que busca responder y con este objetivo es que hace recepción de las filosofías de su tiempo.

Bobichon nos ofrece un elenco de las críticas provenientes del ambiente pagano de las que se hace eco Justino ${ }^{7}$, señalando que, si bien en el Diálogo con Trifón Justino se esfuerza en mostrar la verdad del mensaje cristiano, en la Apología, debe probar no solo la verdad de la doctrina cristiana, sino también la injusticia que se comete contra los cristianos, razón por la cual el debate sobre los contenidos es solo un aspecto en esta obra.

Justino distingue los mitos de los poetas de las enseñanzas filosóficas. Los mitos son obra de la inspiración de los demonios ${ }^{8}$ y desprovistos de pruebas $^{9}$ mientras que la filosofía, si bien tiene numerosas debilidades (contradicciones) $)^{10}$ y ausencia de real demostración, sin embargo contiene parte de verdad, sea que la tomó desde los profetas ${ }^{11}$ o que

hacia el 165, por lo que Benko señala que Galeno podría haber conocido lo que él enseñaba. Cf. S. Benko, Pagan Rome and the early Christians, B. T. (Batsford, London, 1985) 145.

7 Bobichon, Ph., "Les ensegnements juif, païen, hérétique et chretien dans l'oeuvre de Justin Martyr", Revue des Études Augustiniennes, 45 (1999), 233-259, pp. 243-244.

8 Apol. I 21, 6; 25, 3; 54, 1.6; 56, 1; 64, 1; II 5, 5; Dial. 69-70.

9 Apol. 54, 1.

10 Apol.I 4, 8.9; 7, 3; II 10, 3; 13, 3; Dial. 1, 5; 2, 2.

11 Apol. I 44, 8; 59, 1-5; 60, 1s Esta teoría ya estaba presente en el judaísmo helenístico. 
la recibió del $\operatorname{Logos}^{12}$ a través de sus semillas que le fueron acordadas a los que se dedican a ella, y les han valido del odio de los demonios ${ }^{13}$. Las enseñanzas de la filosofía por lo tanto son insuficientes (Bobichon agrega: secundarias o transitorias) ${ }^{14}$. El juicio es más suave que para las enseñanzas de los maestros judíos: es en la sabiduría griega que él ha hecho parte de su camino y es a los lectores paganos que se dirige la Apología. Hay entre las tradiciones rabínica y cristiana una relación de ruptura, entre la enseñanza del Verbo y de los filósofos una relación de inclusión y continuidad.

En esta continuidad se apoya para mostrar la racionalidad ${ }^{15}$ del cristianismo, una racionalidad superadora ${ }^{16}$ incluso de la pagana, por tener su origen en Dios mismo:

"Así, pues, es evidente que nuestra doctrina sobrepasa toda humana enseñanza, por la sencilla razón de que el Verbo entero, que es Cristo, aparecido por nosotros, se hizo cuerpo, razón y alma" (Apol. II 10, 1)

Con esta convicción de la racionalidad del cristianismo y en el marco didascálico-apologético inserta los aportes de la filosofía a su reflexión teológica. Tomaremos dos temas en los que puede verificarse esto.

\section{El tema de Dios en Justino}

Para Justino el tema de Dios es el tema principal de la filosofía, tal como lo afirma al principio del Diálogo con Trifón: “¿no tratan de Dios los filósofos en todos sus discursos y no versan sus disputas siempre sobre su unicidad y providencia? ¿O no es objeto de la filosofía el investigar acerca de Dios? Ciertamente -le dije" 17 .

La convicción acerca de la centralidad del tema de Dios en la filosofía aparece en boca del judío helenizado, conciente del espíritu que animaba

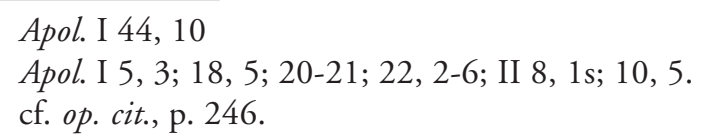

Apol. I 55, 8: "Ahora bien, una vez que los hemos exhortado por la vía del razonamiento y por una figura patente, en cuanto nuestra fuerza lo ha consentido"; 68, 1: "Ahora, pues, si les parece que tales doctrinas son conformes a la razón y a la verdad, tómenlas en consideración".

16 Apol. II 15, 3: "Porque no son nuestras doctrinas, juzgadas con juicio discreto, vergonzosas, sino superiores a toda humana filosofía".

17 Dial. 1, 3-4. 
las corrientes filosóficas de tu tiempo, y es compartida por Justino a través de su inicial asentimiento. Sin embargo, inmediatamente, Justino pone reparos: la mayoría de los filósofos no se ocupan de esto, centrando la consideración filosófica acerca de Dios en su unicidad y providencia. La objeción de Justino tiene como trasfondo el encuentro de la filosofía con la revelación: la filosofía de su tiempo tiende a la afirmación de una entidad divina suprema, pero no única, sino cabeza de hipóstasis subordinadas, mientras que el monoteísmo bíblico exige unicidad divina. El problema de la providencia no era ajeno a las especulaciones y discusiones filosóficas, pero las propuestas solo alcanzaban la afirmación de una providencia genérica; la providencia respecto de los individuos supone la afirmación del carácter personal de Dios, que no solo rige al universo con inteligencia, sino que voluntariamente interviene en la historia, y esto llega a través de la revelación. La teología de Justino parte del dato revelado.

La afirmación del monoteísmo que aparece en el inicio del prólogo, siguiendo el estilo del diálogo platónico según el cual hay que establecer los puntos de acuerdo para que halla un verdadero diálogo, es el punto de encuentro con el judío que permite, como base común, entablar el diálogo. Pero de cara al judaísmo, deberá mostrar la verdad de que Dios tiene un Hijo, novedad cristiana en la concepción de Dios, y en la explicación de esta verdad, recurrirá tanto a argumentos bíblicos como filosóficos. Frente al mundo pagano deberá justificar el monoteísmo, afirmando la absoluta trascendencia de Dios, para lo cual recurre a argumentos que la misma filosofía le proporciona, y así busca lograr un asentimiento desde la racionalidad. Finalmente, de cara a las interpretaciones heterodoxas dentro de la Iglesia, intentará mostrar la verdadera comprensión de la identidad de Cristo.

Uno de los puntos característicos de la teología de Justino es la afirmación de la trascendencia divina, que es descripta con un conjunto de atributos negativos. El primero que proponemos considerar es árretos. En Apol. I sostiene: "Lo cual no solo lo tenemos por cosa irracional, sino que se hace con insulto a Dios, pues teniendo Él gloria y forma inefable, se da nombre de Dios a cosas corruptibles" ${ }^{18}$. Este atributo es privilegiado entre los autores del medioplatonismo para afirmar la trascendencia

18 Justino, Apol., I, 9, 3. También lo usa en el capítulo 61, 10-11: "Porque nadie es

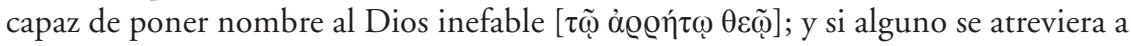
decir que ese nombre existe, sufriría la más imprudente locura”. 
divina de cara al inmanentismo estoico, así lo podemos observar por ejemplo en el Didaskalikos: "Es inefable y captable por el solo intelecto"

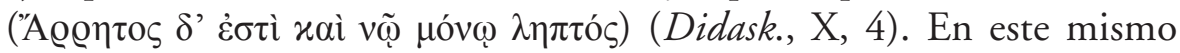
capítulo, que corresponde a la teología del manual, aparecerá dos veces más mencionado el atributo, claramente destacado en relación a los otros. Podríamos afirmar que Justino lo toma de esta tradición y en esa línea se distancia de la visión estoica de la divinidad al punto tal que, respecto de su relación con el maestro estoico, afirma: "pero dándome cuenta que nada adelantaba en el conocimiento de Dios, sobre el que tampoco él sabía palabra ni decía ser necesario tal conocimiento"19.

\section{Hacia el final del Diálogo con Trifón afirma:}

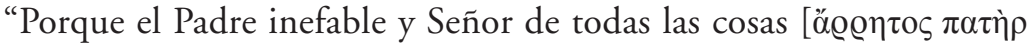

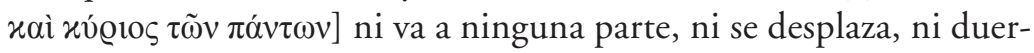
me ni se levanta, sino que permanece siempre en su propio lugar -dondequiera que este se halle-, mirando con penetrante mirada, oyendo agudamente, pero no con ojos ni orejas, sino por una potencia inexpresable. Todo lo vigila, todo lo conoce, y nadie de nosotros le está oculto, sin que tenga que moverse Él, que no puede ser circunscrito en ningún lugar, ni siquiera en el mundo entero, y era antes de que el mundo existiera"20.

La inefabilidad de Dios está unida en este párrafo a su señorío, seguida de una afirmación de la inmutabilidad e incorporeidad. La inmutabilidad es sostenida principalmente en el plano espacial. El contexto del párrafo es la demostración de que no fue el Padre quien se manifestó en las teofanías sino el Logos, puesto que el Padre no puede ser circunscripto en el espacio, puesto que existe antes que el mundo que habría de circunscribirlo. Según Goodenngough este argumento sería de origen filoniano ${ }^{21}$, pero también se encuentra de modo semejante en el Didaskalikos, donde se sostiene que Dios debe ser incorpóreo por el

19 Dial. 2, 3.

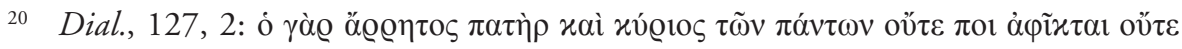

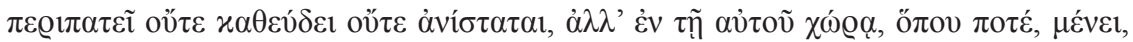

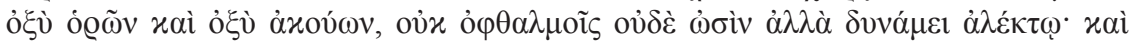

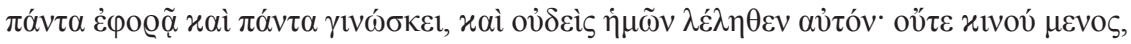

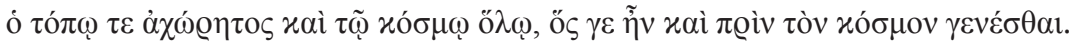

21 Cf. E. Goodenough, The Theology of Justin Martyr, Amsterdam (Phylo Press, 1968) 125. 
carácter absurdo de considerar a Dios posterior a la materia ${ }^{22}$. El contexto de esta afirmación en el Didaskalikos es una sección del capítulo $\mathrm{X}$ donde se proponen atributos negativos no obtenidos a través de la vía katáphairesin, sino que son recogidos de la tradición. Esto manifiesta que este tipo de argumentos pertenecen a un patrimonio común, compartido por los autores platónicos en polémica con la concepción materialista de Dios sostenida por los estoicos, con lo cual no es posible determinar con certeza la fuente desde donde lo toma Justino. Lo que sí es evidente, es su preferencia por la filosofía platónica para presentar su visión de Dios, y la distancia crítica con el estoicismo. Esta distancia es presentada explícitamente en el siguiente párrafo:

"y los filósofos llamados estoicos tienen por dogma que Dios mismo ha de resolverse en fuego y afirman que nuevamente, por transformación, volverá a nacer el mundo. Pero nosotros tenemos a Dios, creador de todas las cosas, por algo superior a todos los seres que experimentan transformaciones" 23 .

Según esto, Dios no es solo inmutable en sentido local sino también en cuanto a su naturaleza: no puede sufrir transformaciones, y este tipo de concepción él mismo la identifica con la noción platónica de Dios: "Lo que siempre es del mismo modo e invariablemente, y es causa de la existencia de todos los demás, esto es propiamente Dios" (Dial. 3, 5). La doctrina de la inmutabilidad de lo divino es claramente de origen platónico, pero en Justino es recibida según la presentación de sus contemporáneos platónicos: para Platón, lo inmutable, lo que siempre es del mismo modo, son las realidades en sí, las esencias, que se identifican con lo divino plural, mientras que el atributo de inmutabilidad es atribuido al Sumo Dios por los medioplatónicos -el segundo Dios estaría afectado por algún tipo de mutabilidad, puesto que actualizado por el primero, aun cuando esta actualización no se verifique como un acontecimiento temporal, sino eterno, la presencia del paso de la potencia al acto implica mutación-.

En Apol. II, 12, 4 reencontramos el atributo árretos asociado a otro:

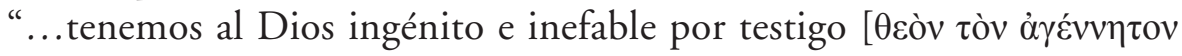

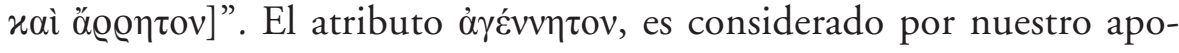
logista exclusivo de Dios, y por medio de él explica la innominabilidad divina. Dios es inefable porque es inengendrado, por lo tanto, todos

22 Cf. Didask., X, 7-8.

23 Apol. I, 20, 2. 
los términos que utilizamos para nombrar a Dios no son propiamente nombres, sino apelativos:

"El Padre del universo, ingénito como es, no tiene nombre impuesto, como quiera que todo aquello que lleva un nombre supone a otro más antiguo que se lo impuso. Los de Padre, Dios, Creador, Señor, Dueño, no son propiamente nombres, sino denominaciones/

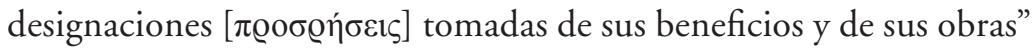
(Apol. II 5[6], 1-2) $)^{24}$.

Así como no podía ser circunscripto en el espacio, por preceder al mundo, tampoco puede ser nominado, por su precedencia absoluta a cualquier realidad, puesto que es ingénito. Solo se lo puede designar mediante atributos obtenidos a partir de sus obras, de por vía de causalidad y analogía. Así obtenemos atributos positivos de Dios, como es el de Padre y artífice del universo ${ }^{25}$, dupla que, como se ha mostrado en otros trabajos, pertenece la presentación medioplatónica ${ }^{26}$. En el Didaskalikos también se afirma que estos atributos divinos son obtenidos por vía kat’analogían. Respecto de la designación "Dios”, no es nombre, pero tampoco es obtenida por analogía, sino que se trata de "una noción implantada en la naturaleza humana para designar una realidad difícil de explicar" (Apol., II, 5 [6], 3) ${ }^{27}$. La expresión "noción implantada"

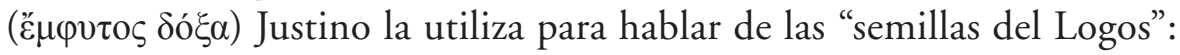
"Y es que los escritores todos solo oscuramente pudieron ver la reali-

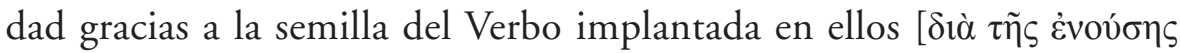

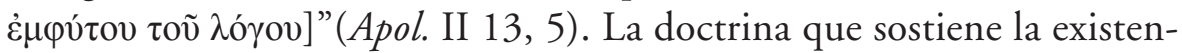
cia de nociones innatas en el hombre es de origen estoico, a esas nocio-

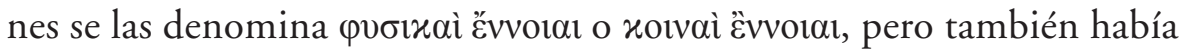
sido asumida por los medioplatónicos de modo adaptado a su cosmovisión. Así la encontramos en el capítulo IV del Didaskalikos: las physikai

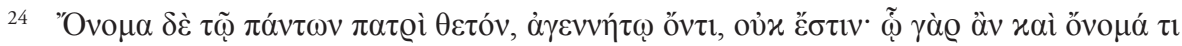

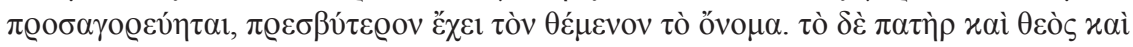

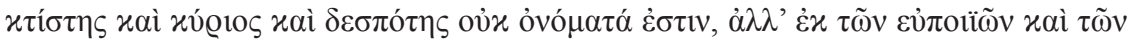

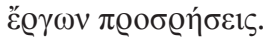

Cf. Apol., I, 8, 2.

Cf. Didask., IX, 1 (p. 163, 13s); X, 3 (p. 164, 40); XVI, 2 (p. 171, 33s); MÁXIMO DE Tiro, Diss. 35. 1 (p. 403. 2-10 H). Se puede ver V. Félix, "La influencia del platonismo medio en Justino a la luz de los estudios recientes sobre el Didaskalikos" en M. Vinzent (ed.) Studia Patristica LXV vol. 13 (pp. 63-78), p. 72.

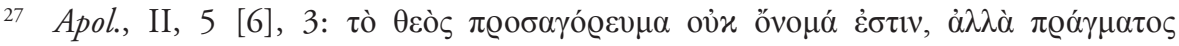

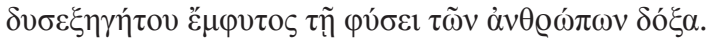


ennoiai están en la inteligencia desde el nacimiento son participación en el hombre de las Ideas divinas, presentes por reminiscencia ${ }^{28}$.

El fundamento de la innominabilidad de Dios había sido puesto en

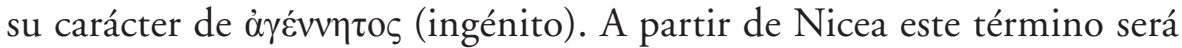
aprovechado por la teología para distinguir al Padre del Hijo, utilizando

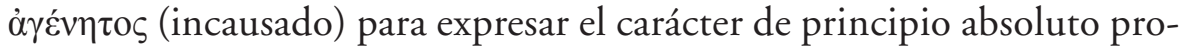
pio de Dios, causa de todo lo demás. Este último término muy usado por Filón y por Aristóteles, no aparece en Justino, que siempre utiliza

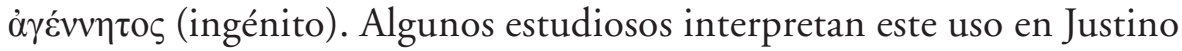
de ingénito como inoportuno cuando debería usar incausado, y esto sería en razón de su pobre formación filosófica que no le permitiría distinguir entre ambos, ya que solo conocería el término de oído ${ }^{29}$. Pero este juicio está condicionado por el presupuesto de que en la síntesis que Justino hace entre filosofía y Escritura, particularmente en su teología, tiene como fuente principal a Filón. Sin embargo, hasta donde hemos podi-

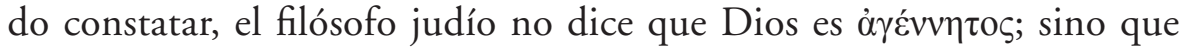

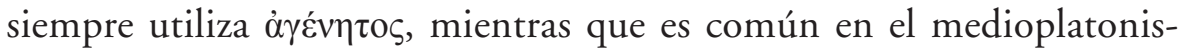
mo referirse a Dios como ingénito, y en composición con à $\theta$ ávatos o $\ddot{\alpha} \varphi \theta \alpha \varrho \tau o \varsigma$, como lo podemos observar en Plutarco y Galeno ${ }^{30}$. Este es el

28 Cf. Didask. IV 8. También encontramos la expresión en GALENO en De libris pro-

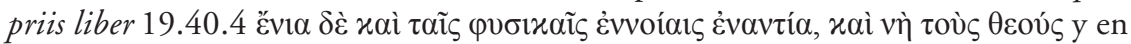
Plutarco: Fragmenta 215 f.2, refiriéndola a los estoicos

29 Cf. E. Goodenough, op. cit., pp. 129-130 quien critica el uso de Justino de

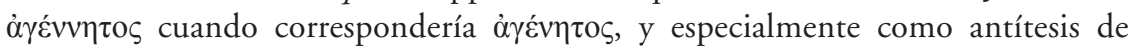

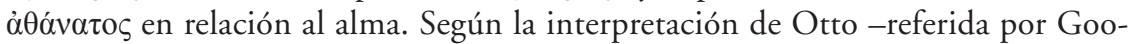
dennough- se trataría de un error del copista. Pero aún si fuera así, cosa que no se ha comprobado, esto no validaría la atribución a Filón como fuente y se mantiene la particularidad del uso que hace Justino del término en relación al Padre, y en combinación con otros que podrían indicar una intencionalidad en nuestro autor. También Simonetti, siguiendo a Barnard, tiende hacia esta interpretación, recono-

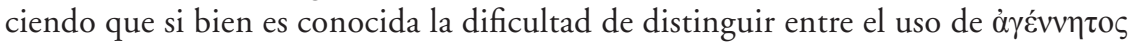

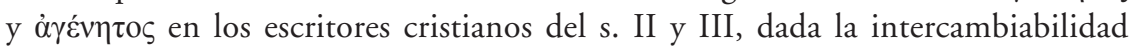
sustancial de los dos términos que solo en el siglo IV serán exactamente distinguidos en el ámbito trinitario, y también la confusión que fácilmente se verificaba en su transcripción; sin embargo le parece acertada en Justino la preferencia por

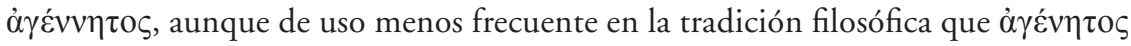
para indicar que Dios no tiene inicio. (cf. M. SimonetTI, Studi sulla cristologia del II e III secolo, Col. Estudia Ephemerides Augustinianum 44, Institutum Patristicum Augustinianum, Roma, 1993, p. 74 n. 12).

30 Cf. Galeno, In Hippocratis de natura hominis librum commentarii, III, 15, 29 y 37; Plutarco, De Iside et Osiride, $359 \mathrm{D}$. 
sentido que también tiene para Justino, y lo tomaría de sus contemporáneos platónicos. Reforzando esta idea, con Daniélou, destacamos el particular uso que Justino hace del término: lo reserva al Padre y en algunos casos en oposición al Hijo ${ }^{31}$; así en Apol., II, 13, 4: "nosotros adoramos y amamos, después de Dios, al Verbo, que procede del mismo Dios ingénito e inefable" 32 . El término no designaría, por lo tanto, algo que caracteriza lo inteligible en general como en los medioplatónicos, sino

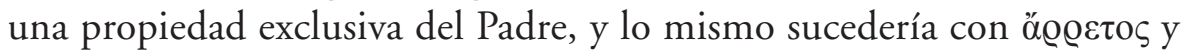

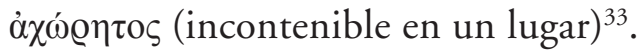

\section{LA CRISTOLOGía}

Así hemos llegado desde la concepción de Dios a la cristología de Justino. El Padre, de carácter trascendente, se vincula al mundo a través de su Hijo:

"En cuanto a su Hijo, aquel que solo propiamente se dice Hijo, el Verbo, coexistente con él, engendrado [ $\gamma \varepsilon v v \omega ́ \mu \varepsilon v o s]$ por Él antes que las criaturas, cuando al principio creó y ordenó por su medio el universo, se llama Cristo por su unción y por haber Dios ordenado por su medio todas las cosas; este nombre comprende también un sentido incognoscible [...]. 'Jesús', en cambio, es un nombre que significa al mismo tiempo hombre y salvador" ${ }^{34}$.

El Hijo es engendrado y por esto puede tener nombres: Cristo y Jesús. La explicación que ofrece de ambos remite a su rol mediador. El nombre Cristo designa su carácter de mediador en la creación, entendida como ordenación, función demiúrgica y en cuanto refiere al Padre permanece en cierto sentido incognoscible. El nombre Jesús, pone el acento en su dimensión cognoscible, lo designa en cuanto hombre, y señala su carácter de mediador en la salvación.

No son los únicos nombres que recibe. En el Diálogo con Trifón recoge una serie de nombres que vinculan a Jesús con el AT, con un fin

31 Cf. J. Daniélou, 321-322.

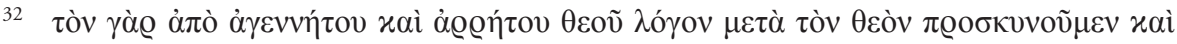
$\dot{\alpha} \gamma \alpha \pi \tilde{\omega} \mu \varepsilon v$.

33 Cf. Justino, Dial., 127, 2.

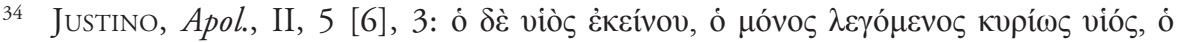

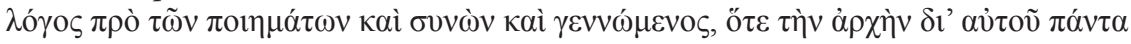

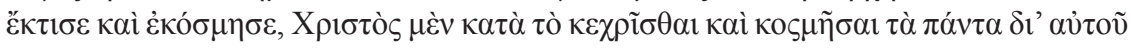

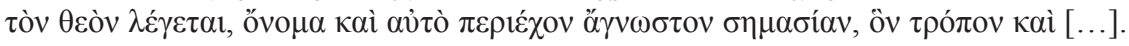

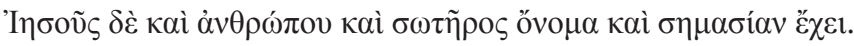


apologético: mostrar a los judíos como Cristo había sido anunciado proféticamente. Allí leemos:
“(...) Dios engendró, como principio antes de todas las criaturas ${ }^{35}$,

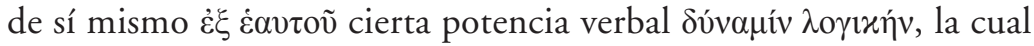 es llamada también por el Espíritu Santo "Gloria del Señor", y unas veces hijo, otras sabiduría, ora ángel, ora Dios, o bien Señor y Logos; y ella se llama a sí misma "jefe del ejército", cuando se aparece en forma humana a Jesús (Josué), hijo de Navée ${ }^{36}$. Así que todas estas denominaciones le vienen por estar al servicio del designio del Padre

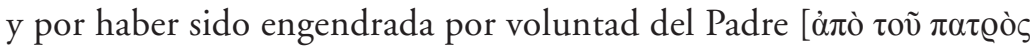

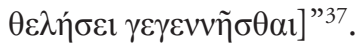

La multiplicidad de nombres indican los distintos modos de servir al Padre, distintas facetas de su función mediadora. El Hijo, engendrado eternamente "desde el Padre" y por su voluntad y en orden a su función mediadora. El Hijo también recibe el apelativo de Dios, como ya señalamos antes, no es un nombre propiamente, sino una noción implantada. Simonetti destaca el fin apologético que Justino se propuso con este razonamiento de disminuir el tradicional valor atribuido al nombre de Dios respecto al concepto expresado con el nombre: implícitamente disminuye, en polémica con Trifón, el significado del rígido monoteísmo judío, en beneficio de una concepción más articulada de la divinidad ${ }^{38}$. El Hijo es Dios numéricamente distinto del Padre: "el Verbo muestra (así) que este retoño fue engendrado por el Padre absolutamente antes de todas las criaturas; ahora bien, todo el mundo convendrá en que lo engendrado es numéricamente distinto del que lo engendra” (Dial. 129, 4). Pero subraya también que la diferencia numérica no supone separación. Con esto busca por un lado dejar clara la divinidad de Cristo de cara al judaísmo, y por otro no caer en un politeísmo.

Solo una breve alusión al nombre de Logos, que probablemente sea el punto más destacado de la integración de la filosofía en la teología

\footnotetext{
35 Cf. Gn 1, 1; Pr 8, 22; Col 1, 15.

36 Cf. Jos 5, 13.

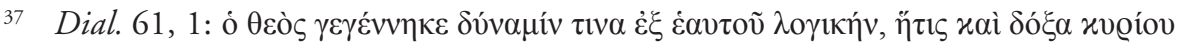

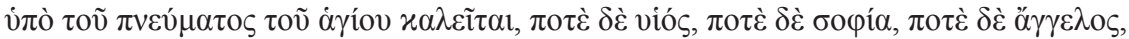

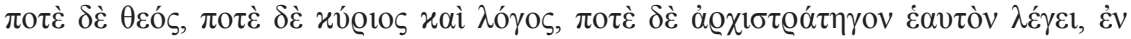

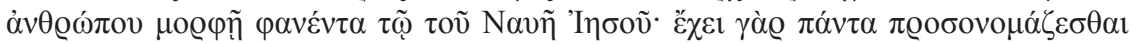

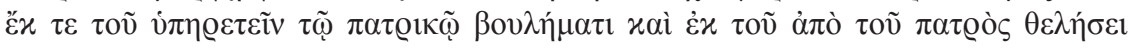
$\gamma \varepsilon \gamma \varepsilon v v \tilde{\eta} \sigma \theta \alpha$.

38 Cf. M. Simonetti, 79.
} 
de Justino, respecto de la cual ya hemos hablado en otra instancia ${ }^{39}$. El nombre lo designa en su función de mediador en la creación y en la revelación ${ }^{40}$ : el Padre se revela por medio del Hijo Logos, a través de sus semillas participadas por todos los hombres desde la creación, por medio de los profetas y las teofanías en el AT, y en última y plena instancia, en la encarnación, pero siempre es el mismo quien enseña a los hombres la verdad, Cristo, y por lo tanto el verdadero maestro de la única filosofía, la cristiana, que alcanza su cometido como tal: hablar de Dios.

\section{A MODO DE CONCLUSIÓN}

A partir de lo considerado podemos señalar algunos elementos conclusivos:

En su intento por mostrar la racionalidad del cristianismo recurre repetidamente y en distintas instancias a los atributos que le provee el medioplatonismo para realizar una descripción de Dios, en polémica con la visión estoica.

De esos atributos se sirve con cierta libertad haciendo un uso específicamente cristiano en lo que respecta a la reflexión trinitaria y principalmente cristológica.

Respecto de los nombres referidos al Hijo podemos hacer dos observaciones. Por un lado estos son tomados de la revelación, por lo tanto su reflexión es propiamente teológica, aunque el tenga la pretensión de presentarla como filosofía, el recurso a la filosofía está al servicio de teología y en función apologética y kerigmática. La segunda observación es que en la propuesta de Justino de atribuir la diversidad de nombres a las diversificaciones que recibe su función de mediador entre el Padre y el mundo se puede ver un antecedente de la doctrina de las epinoiai de Orígenes.

Así, su intento de caracterizar al Hijo en relación al Padre sirviéndose de la filosofía, a través de un diálogo fructífero a nuestro juicio entre razón y fe, le ha permitido realizar progresos en la reflexión teológica de los cuales se servirán y profundizarán los pensadores cristianos posteriores.

39 Cf. V. FÉlix, "La cristología del Logos en Justino mártir”, en I Congreso de estudios patrísticos (Actas) (San Juan, Argentina, 2012).

40 Cf. M. FÉdou, "La doctrine du Logos chez Justin: enjeux philosophiques et théologiques" (Kentron n. 25, 2009) 145-158. 
